\title{
Strengthening mycology research through coordinated access to microbial culture collection strains
}

\author{
D. Smith *1), A. Kermode, G. Cafà, A. G. Buddie, T. S. Caine and M. J. Ryan
}

\begin{abstract}
Well-managed genetic resources and associated metadata are essential to underpin research addressing the challenges to food security, healthcare, climate change, biodiversity, environment, education and our bio-based economy. Culture collections have supported microbiology research for over 100 years, whether they are collections belonging to individual scientists or institutional repositories. The 790 collections registered with the World Data Centre for Microorganisms (WDCM) together hold over three million strains representing a wide range of microbial diversity. This review provides an overview of the uses and outputs of collections that support work in mycology, agriculture and the environment. Further, it focusses on the advantages of coordinating efforts and establishes recommendations to improve resource provisions for research and the development of the necessary infrastructure. The CABI living resource collection provides an example that holds over 28,000 strains of fungi from 100 years of research in mycology. In the modern era, microbial interventions and solutions require knowledge not only of those microorganisms that can be grown and preserved axenically but also whole microbial communities: i.e. 'microbiomes.' Current technologies enable us to access this latter, hidden resource, thereby facilitating a better understanding of how to harness and manipulate microbial communities to improve crop yields and allow successful interventions such as biocontrol of pests, diseases and invasive species. The WDCM Analyzer of Bio-resource Citations reports that 79,224 strains from 131 collections from 50 countries have been cited in 145,133 papers published in 50,307 journals from January, 1953 until April, 2020. These organisms have a multitude of uses, for example as sources of antibiotics, therapeutic drugs and other active agents. They have been applied widely including in the biodegradation, bioremediation, biotransformation and biotreatment of wastes. Further uses include interventions in agriculture for soil and plant health or biological control of pests and diseases. All of the above may be achieved by individual institutions but, by working together, collections can form a critical mass to focus on key global issues and can achieve much more. Mechanisms are suggested for coordinating collections in order to deliver a more comprehensive support system in the advancement of science and innovation.
\end{abstract}

Keywords: Agriculture, Biocontrol, Biological Resource Centre, Biotechnology, Culture collection, Microbiome, Microorganism

\section{Background}

The aim of this review paper is to take the landmark of 100 years of mycology at CABI as a basis for considering how culture collections have changed over the years to meet evolving needs of an ever-changing user CABI, Bakeham, Lane, Egham, UK community. 
The first public service microbial culture collection was established, in 1890, by Professor Frantisek Kral at the German University of Prague, Czech Republic (Sly et al. 1990). Over the course of the next 130 years, the number of culture collections has risen massively to almost 800 culture collections in 77 countries registered with the World Data Centre for Microorganisms (WDCM), which together hold 3,157,910 strains of a wide range of microorganisms (http://www.wfcc.info/ccinfo/). Despite this impressive number of strains being held in institutions, the number pales in significance when compared with the total number of microbial strains used in scientific research. Stackebrandt (2010) reported only 190 strains $(0.94 \%)$ of the 20,200 strains listed in 8835 articles in issues of eight European microbiology journals in 2008 had found their way into public collections. This is a huge missed opportunity for the scientific community as a whole, it is crucial for the benefit of science, future study and the confirmation of published research that the strains on which the published science hinges are maintained in a stable condition for future use. Stackebrandt et al. (2014) went on to provide a sound case for journal editors to reinforce good practice, the requirement that strains cited in published research should be deposited in recognised public service collections and thus be available for scientific study (Becker et al. 2019). This apparent lack of understanding of the value of depositing organisms for future study is exemplified by the fact that the strains that have been deposited, to date, in the WDCM collections represent less than $25 \%$ of the species currently described and represents a very small proportion of the number of taxa estimated to occur in nature e.g. current estimates are for up to 3.8 million species of Fungi (Hawksworth and Lücking 2017), up to $5.1 \mathrm{M}$ according to Blackwell (2011) and up to one million species of Prokaryotes (Louca et al. 2019).

The CABI collection is just one of several global culture collections each with such history and holdings as a result of researchers depositing microorganisms for future study and use in biotechnology. Yeasts have been harnessed by humans in bread, beer and wine making for thousands of years (Alba-Lois and Segal-Kischinevzky 2010). Other food applications include large-scale production of food and industrial products such as beverages, antibiotics, milk by-products such as cheese (Jay et al. 2005) and fermented foods including yogurt or sweet chocolates (https://www.sciencedirect.com/topics/ food-science/fermented-food). Scientists continue to isolate and investigate the properties of organisms and today they are used as sources of therapeutic agents (Demain and Sanchez 2009), probiotics which may remediate diseases of digestive systems and intestinal disorders (Fenster et al. 2019), biologicals such as insulin (Baeshen et al.
2014), serum antibodies, essential hormones and biopharmaceuticals (Jozala et al. 2016). Collections hold production strains for enzymes and fine chemicals such as polysaccharides, polyamides, polyesters and many other varieties of biopolymers (Kreyenschulte et al. 2014). Single-and mixes of-organisms are important in biodegradation, bioremediation and biotransformation (Das 2014). Microbes are also used in the cleaning of environments and biotreatment of wastes e.g. removal of heavy metals, production of industrial enzymes and for many other products. Importantly, 'reference' strains for taxonomy and key strains from publications that must be retained and stored for future use need to be maintained in stable conditions for reproducibility to confirm results and as the basis for further work (Overmann and Smith 2017).

The present review: (1) provides an overview of the use and output of representative collections to show how they are addressing current needs; (2) makes recommendations for future activities to enhance the resources that underpin research and how the available infrastructure could be developed further in order to better meet these needs; and (3) seeks to influence policy through the development of community support and how this could lead to more appropriate funding levels. Individual collections lack the capacity to provide comprehensive coverage and/or store all key research strains (Stackebrandt et al. 2014). As such, a coordinated strategy with appropriate supporting infrastructure is needed to address this critical pitfall. The authors draw from their direct experience of the CABI collection, its involvement in collaborative projects and the networks in which it participates in order to appraise the past and present, whilst considering the potential future of culture collections.

\section{The CABI collection}

$\mathrm{CABI}$ is an international not-for-profit organisation (https://www.cabi.org/), owned by 49 member countries; it improves people's lives by providing information and applying scientific expertise to solve problems in agriculture and the environment. Through knowledge sharing and conversion of science to practical solutions, CABI improves global food security by helping farmers grow more and lose less produce, combating threats to agriculture and the environment from pests and diseases, protecting biodiversity from invasive species, and improving access to agricultural and environmental scientific knowledge. To underpin these activities, it has built up a living collection of 28,000 fungi and 2000 bacteria strains over its 100 years of research and development in the field.

The CABI culture collection began as a series of individual collections held by institute mycologists (Fig. 1). These were brought together in 1935 by Major H.A. Dade 


1920-1935 Scientists maintained their own strains
$1935-1946$ Major Dade consolidated the collections
1947 Received strains from the Lister Institute as the National Collection of Fungus Cultures
1965 Freeze-drying introduced
1968 Liquid nitrogen cryopreservation introduced
1982 Establishment of Biochemistry and Industrial laboratories for sustainability
1983 International Depository Authority
1983 Accreditation to ISO 17025 for tests within Media Preparation and Industrial services
1986 Cryomicroscopy first performed on fungi
1989 Cessation of National funding, establishment of CABI-based business model
1996 UKNCC Quality Management System implemented
2000 Membership of CABRI audit to CABRI Guidelines
2008 GBRCN founder member
2010 MIRRI partner
2012 ISO 17025 Accreditation of molecular identification of bacteria
2013 ISO 17025 Accreditation of molecular identification of fungi
2015 Introduced Next Generation Sequencing (NGS) platform (Illumina MiSeq) and Matrix-
Assisted Laser Desorption/lonisation Time-of-Flight Mass Spectrometry (MALDI-ToF-
MS) Biotyper (Bruker)
2017 CABI and Rothamsted Research launch UK Plant Microbiome initiative
2019 Joined RBG, Kew on the Wellcome Trust-funded Darwin Tree of Life Genome
Sequencing Project.

Fig. $1 C A B I$ from culture collection to $m B R C$

and, in 1947, the collection took on the remit of managing the UK National Collection of Fungus Cultures. At that time the non-medical fungal component of the National Collection of Type Cultures (NCTC) at the Lister Institute, comprising over 700 cultures was transferred to CABI (Report 1947). Dade incorporated these strains into the collection using continuous growth techniques to maintain and store them under oil (Smith and Onions 1994). Later curators developed the capabilities further: Onions introduced freeze drying and cryopreservation in the 1960s, with Smith undertaking further development and optimisation of these techniques for filamentous fungi (Smith and Onions 1994), whilst Ryan extended cryopreservation techniques to Oomycetes (Ryan et al. 2012, 2014). The collection's expansion reflected the activities of the CABI mycologists of the time and by the 1990s it housed more than 20,000 strains; it has continued to grow to its present level of 28,000 fungi and 2000 bacteria. CABI undertook the role of providing this resource not only to underpin UK research but also as part of its commitment to its 49 member countries to enable the resource to be available globally. In 1959 the collection supplied around 1500 strains to industry and academia and since then an average of 2000 strains have been supplied externally each year and a similar number supplied internally for research. Since 2000, CABI has focussed on supplying strains in bulk for research programmes, large-scale bioactive screening and for helping to establish collections abroad. Currently, the CABI collection is providing strains for the Wellcome Trust's Darwin Tree of Life project with the Royal Botanic Garden (RBG), Kew (https://www.sanger.ac.uk/science/ programmes/tree-of-life) to deliver the fungal component in the UK-wide initiative to sequence the genomes of all 60,000, complex species (eukaryotes) in the British Isles. CABI has identified 1375 strains from its collection that meet project requirements and that are available for sequencing. The initial phase focuses on representatives at the family level and CABI will provide 2-300 strains; the remainder are available for further phases of the project.

A service for the identification of fungi was set up in 1920, when the Imperial Bureau of Mycology was established at Kew, later renamed as the Imperial Mycological Institute. In 1945, E.W. Mason established a Dried Reference Collection of cultures and specimens (Herb IMI Fungarium) and a system for documenting samples was set up, each new sample being assigned a unique number preceded by the 'IMI' code. The first accession to the CABI living culture collection was IMI 605 Curvularia crepini isolated from Ophioglossum vulgatum in the UK in 1945 . Since that time nearly 500,000 voucher specimens have been deposited in the IMI Dried Reference Collection but only around $6 \%$ of the half a million strains were deposited in the living culture collection. One of the most significant of these was IMI 24317, Penicillium notatum (reassigned as Penicillium chrysogenum but now known to be Penicillium rubens). Sir Alexander 
Fleming deposited this as an example of his penicillin producer in the National Collection of Type Cultures as NCTC 6978, in April 1945. This strain was received into the CABI collection when the NCTC collection was taken over by CABI in 1948 and has been kept alive ever since. Fleming's strain was initially transferred on agar until 1956 when it was stored under mineral oil and then freeze-dried in 1976. Since that date the initial batch of ampoules has been the seed stock providing the source material for subsequent restocking, thereby enabling the supply stocks of the strain to be generated only from the original freeze-dried material. Such practices limit the change that could occur due to long-term adaption to growth under laboratory conditions. CABI introduced freeze-drying in 1965 and cryopreservation in 1968 to reduce change in preserved materials. CABI uses mineral oil storage only where there is no alternative, freeze-drying and cryopreservation are used as the main methods of preservation and each strain in the collection is maintained by at least two of these methods or held in at least two locations. For added security, CABI maintains a backup collection of the most important strains which are stored in a separate building elsewhere on the site.

Other organisms of significance maintained in the collection for further study include an example of the fungus that caused the potato famine: Phytophthora infestans. The collection holds many other plant pathogens, these include an example of the Dutch Elm disease fungus, formerly Ceratocystis ulmi now known as Ophiostoma ulmi. IMI 185896 is one of 25 strains of this disease-causing organism deposited enabling critical comparisons to be made over the course of time. It is not just the holdings of one single collection that is important in this respect but by accessing the holdings of the world's collections for such studies valuable information can be drawn and used. Other important strains in the collection include over 40 strains of Hormoconis resinae (now known as Sorocybe resinae) from aviation fuel. The first, deposited as IMI 88968, was freeze dried in 1968 which coincides with the initial recorded occurrences of the fungus in aircraft fuel. The continued availability and variety of strains available of $H$. resinae led to the development of an early warning test kit for the fungus in aircraft fuel. If unnoticed the fungus may compromise the safety of aircraft by blocking fuel systems. CABI's spin-off company, Conidia Bioscience was established to produce the rapid test kit that is sold to airlines to monitor fungal contamination of aircraft fuel tanks and aviation fuel systems. This company has now expanded their coverage to other fuels including diesel and marine systems (https://conidia.com/). CABI's ongoing scientific work with Conidia has included the description of a novel yeast isolated from aircraft fuel (Buddie et al. 2010).
The techniques used to preserve key strains are of critical importance and CABI continues to be at the forefront of preservation protocol development (Ryan et al. 2012, 2014). It is essential that the full potential of the strains is retained. For example, as part of one study, the CABI collection characterised 130 strains that produce 52 different enzymes including, amylase, cellulase, lipase and proteolytic enzymes. If the organisms were allowed to continue to grow for extended periods without the need to express the relevant metabolic pathway, requiring the particular enzyme(s), this property could diminish and be lost through strain drift (Smith et al. 2013).

\section{Examples of research utilising CABI collection strains}

The CABI collection has over 6000 representative strains of plant pathogens collected over time from major crops worldwide that enable a range of studies, for example to observe changes in the pathogen as a result of resistance to fungicides, the use of new plant varieties, changes in the environment or climate change. Recently, this resource has enabled a comparative genomic $\mathrm{PhD}$ study with Imperial College. Work was initiated to gain a better understanding of the evolution of the coffee wilt pathogen, Fusarium xylarioides and the impact of climate change. Historic disease strains had been studied previously at CABI when investigating the population dynamics of the disease (Buddie et al. 2015). Currently, a PhD study at CABI by Lily Peck includes genomic characterization and whole genome sequence comparison have been used to predict the evolutionary response of the coffee wilt pathogen to climate change. Initial results have identified 12 effector genes of interest, which indicate ancestral strains as an outgroup, with Ethiopian and Congo basin strains emerging separately from them.

The ambitious Wellcome Trust-funded Darwin Tree of Life project (https://www.darwintreeoflife.org/) aims to sequence the genomes of all species of animal, plant, fungus and protist in the 'Atlantic archipelago of Britain and Ireland.' This will encompass at least 66,000 species in three phases over the project's envisaged 10-year timeframe. CABI is supplying fungal cultures to the initiative with key partners including Wellcome Sanger Institute, European Bioinformatics Institute, Natural History Museum, London, Royal Botanic Gardens, Kew and Edinburgh, Earlham Institute, Marine Biological Association (MBA) and the Universities of Cambridge, Edinburgh and Oxford. Phase 1 of the project aims to sequence the genome of a member of every family of the eukaryotes found in the UK. Phases 2 and 3 are to obtain genome sequences of a member of all genera and all species, respectively. For the Fungi, the relevant numbers are: 563 families, 3007 genera and 16,082 species. Phase 1 
seeks to obtain at least 115 sequences. The CABI culture collection has UK isolates of $>1300$ species which could be sequenced over the full 10 years of this study. As CABI also holds a number of UK strains of Oomycete species, we will also feed into the Protist part of the tree. Not all species, genera or even families are represented by Culture Collection holdings-indeed, not all described taxa can be cultured. As such, as well as the provision of strains by CABI, Royal Botanical Gardens, Kew and Edinburgh and marine fungi from MBA, targeted collecting will be undertaken by teams of "trusted collectors". Furthermore, there will be a minimum required metadata set, so any gaps in the records of the culture collection strains may require new representatives to be sourced. Given the vast upheaval in fungal taxonomy, nomenclature and classification over the past few years, it is quite likely that a considerable proportion of strains will require reassignment to different species, genera or even families. This will enable taxon gap-filling that will benefit the global mycological research community as not all species have an ITS barcode sequence recorded at the present time.

Another recent study which has seen the benefit of a polyphasic approach to characterisation of fungi was the Pakistan-based investigation into aflatoxin-producing aspergilli. The project was a key proof-of-concept baseline analysis that has led to a broader international collaboration between Pakistan and the USA. The baseline study was undertaken jointly by CABI staff in the UK and in Pakistan. The aim was to obtain some evidence of the degree of potential aflatoxin-producing fungi in the food chain in chili and maize growing regions of Pakistan. Samples of soil from chili and maize growing areas, fresh chili and stored corn cob were screened for the presence of aflatoxigenic aspergilli. The investigation entailed the use of classical isolation and culture-based approaches as well as MALDI-ToF-MS proteomic profiling and the next generation sequencing (NGS) methodologies of ITS rRNA metabarcoding of soil samples plus genome skimming with low coverage to obtain the entire rRNA gene cluster and the full mitochondrial genome of selected isolates (Cafá et al. 2018).

\section{Examples of rescued collections}

Over the years CABI has rescued orphaned collections as their custodians retired or institutions changed their remit and found no use for them. Significant examples of these are the National Collection of Wood-Rotting Macro-Fungi (NCWRF) rescued from the Biodeterioration Section of the Building Research Establishment housed in the Timber Protection Division of the Building Research Station, Garston in 2002. Of the
NCWRF 550 strains of wood destroying fungi, mainly basidiomycetes important in the biodeterioration of wood only those in liquid nitrogen were transferred. Attempts to freeze cultures on agar failed and currently 72 strains are available in from the CABI open collection. The dried specimens are now with the Royal Botanic Gardens, Kew. Another example is the University of Reading's Aquatic Phycomycete Culture Collection, incorporated in 2002. The collection was catalogued in 1999 as part of the transfer process and comprised over 650 strains in water storage, 476 of which were recovered, purified and incorporated into the CABI living collection. Key genera included Achlya, Aplanopsis, Brevilegnia, Dictyuchus, Leptolegnia, Pythiopsis, Pythium, Phytophthora, Saprolegnia and Thraustotheca. Only those strains that could be preserved by longer term methods of oil and cryopreservation could be maintained as CABI did not have the resources available to keep them in water storage. CABI has been working with the British Antarctic Survey (BAS) to maintain part of the BAS microbial collection which was shared with CABI in 2006. The 600 plus strains transferred to CABI included almost 90 strains of the genus Phytophthora representing 26 species, including some plant pathogens.

Such examples of rescuing collections are not unique. The US Culture Collection Network (USCCN) report several successful rescue acts (Boundy-Mills et al. 2019). They remark that a very common cause of loss of a private research collection of microbes is retirement of the researcher who has built up or maintained the relevant collection without any plan for the collection's future thereafter. The Fungal Genetics Stock Center has accepted entire collections such as that of Nobel prize winner E.L. Tatum. The Phaff Yeast Culture Collection at UC Davis was able to incorporate over 2600 unique strains when two researchers faced retirement one at Syracuse University and another from New York; the University of Texas Culture Collection of Algae Collection has rescued nearly 1000 algal strains from eight important research collections. The ARS Culture Collection (NRRL) has been able to acquire numerous research and institutional collections of microbes. Amongst the key collections that might otherwise have been lost to science were the Blakeslee collection of Mucorales, the Mix collection of Taphrina, the US Army Quartermaster collection of filamentous fungi, the Smith collection of rhizobia, the International Streptomycete Project collection, the Waksman collection of Actinomycetales, and the Fell collection of marine yeasts (Boundy-Mills et al. 2019). 


\section{Development of the global community of culture collections}

Most culture collections endeavour to keep pace with advancing technologies and the needs of users. Several well-known collections have led the way, including the American Type Culture Collection (ATCC), the Centraalbureau voor Schimmelcultures (CBS, recently renamed as the Westerdijk Fungal Biodiversity Institute), the Institute Pasteur (IP), Agricultural Research Service (ARS) Culture Collection (NRRL) and, of course, the CABI resource that was formerly the Commonwealth Mycological Institute (CMI) and then the International Mycological Institute (IMI) culture collection. These public service collections vary in form and function and have been supporting microbiology since the late 1800s (Smith 2012). As technologies advance and research needs evolve, collections need to meet new challenges, both scientific and regulatory (Ryan et al. 2019). Whilst providing support to research, collections are challenged to find appropriate business models to enable continuity and sustainability (Smith et al. 2014) and to meet international operational standards (Martin et al. 2015). The World Federation for Culture Collections (WFCC) (http://www.wfcc.info/ index.php/home/) was established about 70 years ago in order to support culture collection development with a set of guidelines for the establishment and operation of culture collections (http://www.wfcc.info/guidelines/). The EU project Common Access to Biological Resources and Information (CABRI) was established to offer worldwide access to partner collection databases producing technical specifications and procedures which define how they should handle each resource type (http://www. cabri.org/). Culture collections evolved to become the modern-day Biological Resource Centre (BRC) as defined by the OECD Biological Resource Task Force that operated from 1999 to 2007 to strengthen their activities to underpin biotechnology (http://www.oecd.org/sti/emerg ing-tech/oecdbestpracticeguidelinesforbiologicalresour cecentres.htm), see Table 1. This group produced best practice guidance (http://www.oecd.org/sti/emergingtech/38777417.pdf) and recommended the establishment of a Global Biological Resource Centre Network (GBRCN). The GBRCN concept was built around a global network of biological resource centres as a critical element of the infrastructure that underpins advances in the biological sciences and their capacity to contribute to sustainable growth. Its aim is to enhance access to biological resources and foster international collaboration in this area, underpinning economic and social development. Efforts to establish a GBRCN independent of the OECD were endorsed by OECD Science and Technology Ministers (http://www.oecd.org/science/emergingtech/towardsaglobalbiologicalresourcecentrenetwork .htm). A proof-of-concept programme (Smith and Fritze 2010; Fritze et al. 2012) funded by the German Federal Ministry of Education and Research (Bundesministerium für Bildung und Forschung, BMBF) led to a European regional Research Infrastructure being established under European Strategy Forum on Research Infrastructures (https://www.esfri.eu/esfri-roadmap).

Although the WFCC linked collections provide mechanisms for enhancement, communication and technology exchange, it was evident that culture collections needed investment to meet the needs of advancing science. The WFCC did not have the resources but the OECD recognised their value and established the BRC task force with the aim to organise a global effort to drive the necessary investment. As the WFCC did not have the mandate to influence and change institutional policy and strategy, the OECD explored mechanisms to enable coordinated action and commitment to deliver common goals. The GBRCN proof of concept successfully demonstrated the

Table 1 Overview of international initiatives strengthening culture collection functioning and collaboration

\begin{tabular}{|c|c|c|}
\hline World Federation for culture collections & Guidelines for the establishment and operation of culture collections & 1968 \\
\hline World Data Centre for Microorganisms & $\begin{array}{l}\text { World Directory and Global register of culture collections with unique } \\
\text { identifiers }\end{array}$ & 1972 \\
\hline Common Access to Biological Resources and Information & CABRI Guidelines and access to the consortium collection databases & 1999 \\
\hline \multirow[t]{3}{*}{ Organisation for Economic Cooperation and Development (OECD) } & Defined Biological Resource Centre (BRC) & 1999 \\
\hline & $\begin{array}{l}\text { Recommended Global Biological Resource Centre Network (GBRCN) as a } \\
\text { coordinated global effort }\end{array}$ & 2006 \\
\hline & Best Practice Guidelines for Biological Resource Centres & 2007 \\
\hline European Commission FP7-Infrastructures-2008-1 & EMbaRC $^{\text {a }}$ project converted OECD BRC guidelines to a draft standard & 2009 \\
\hline German Federal Ministry of Education and Research & GBRCN Demonstration Project proof of concept & 2010 \\
\hline European Strategy Forum for Research Infrastructures (ESFRI) & Defragment European research resources & 2012 \\
\hline Microbial Resources Research Infrastructure (MIRRI) & $\begin{array}{l}\text { Preparatory phase to coordinate European culture collection operation and } \\
\text { standards }\end{array}$ & 2016 \\
\hline
\end{tabular}

a EMbaRC: European Consortium for Microbial Resource Centres, Grant Agreement Number 228310—http://www.embarc.eu/ 
potential of a global network initially bringing together 15 partners in 11 countries and on delivery of the final report 98 collections in 28 countries had expressed interest in joining. The GBRCN final report recommended five main points of action (Fritze et al. 2012):

- Establish national BRCs;

- Develop an accreditation system for BRCs based on international criteria;

- Create international linkages among BRCs;

- Coordinate standards, rules and regulations, taking BRCs into account;

- Establish a global BRC network.

However, funding for such an undertaking was not available so other options were pursued. A regional approach was considered and the GBRCN and EMbaRC consortia worked with National representatives to submit a proposal to ESFRI and as a consequence the European Commission funded the preparatory phase of MIRRI (grant agreement 312251). Following the success of the OECD initiative many public service collections started to declare themselves as BRCs the majority basing this on achieving accreditation to accepted International quality standards and based upon their history of product and service provision. Examples of these were the ATCC, USA; Biological Resource Center, National Institute of Technology and Evaluation (NITE, BRC) Japan; Microbial Culture Collection, University of Helsinki (HAMBI) a microbial domain Biological Resource Centre, Finland; and the members of the UK BRC Network (https://www. ukbrcn.org/).

As an example of the modern BRC, CABI's culture collection adopted the WFCC, and subsequently the Common Access to Biological Resources and Information, guidance (http://www.cabri.org/) and was accredited to ISO Standard 17025 in 1983. More recently, CABI added a suite of technologies for molecular biology and cryobiology to its accredited activities (see Fig. 1); in 2019 CABI underwent transition to the new ISO 17025:2017.

\section{CABI collection underpinning its research in agriculture and the environment}

Today, the primary focus of the CABI collection is to maintain the stability and quality of the microorganisms that underpin the microbiology undertaken in the course of CABI's work. CABI focuses primarily on agricultural and environmental issues in the developing world, and the creation, curation and dissemination of scientific knowledge. This encompasses:

- sustainable economic development through agriculture;
- meeting the increasing global demand for quality food by improving smallholder farmers' access to markets;

- producing climate resilient food and nutrition;

- utilising and conserving a healthy landscape and properly-functioning ecosystems;

- helping people gain access to sufficient, safe and nutritious food;

- researching ways of producing and trading more food with less harmful pesticides, fewer harmful pathogens but more nutritional value.

CABI flagship projects demonstrate how knowledge of plant pathogens and experience in handling and identifying them is crucial. The project Plantwise, which has supported over 30 million smallholder farmers across the world, provides knowledge on ways to lose less of what they grow to pests and diseases, increasing food security and thereby improving rural livelihoods. The Plantwise consortium has set up a sustainable network of over 3700 plant clinics in 34 countries around the world and has trained advisory officers, known as 'plant doctors', to help farmers struggling with plant pests and diseases. The plant doctors provide diagnoses and management advice for any problem and any crop. The plant clinics are not operated by CABI directly, but by CABI's national partners. Plantwise has provided training for over 10,000 plant doctors and it has developed the Plantwise Knowledge Bank (https://www.plantwise.org/KnowledgeB ank) which is an open access gateway to actionable plant health information and services, from diagnostic and management advice to maps of pest locations and customized alerts on pest news. Such activities and training rely upon representative microorganisms being available for use in interventions and references for teaching as well as the associated metadata (Cameron et al. 2016). It is imperative that naming of organisms and diagnoses of disease are correct not only to ensure correct treatments are advised but that disease records for the country are accurate.

As a result of the work undertaken by $\mathrm{CABI}$ in agriculture to improve yields, an extensive range of isolates of beneficial use as well as pathogens of crops has been collected and maintained. The potential of these organisms stretches well beyond their immediate activities and provides a resource for CABI to screen for bioactive compounds and products of relevance to healthcare, food security and bioindustry. Only a very small fraction of the CABI living collection has been screened to date, but already promising results have been observed. Several strains have expressed strong actions against diseases such as Tuberculosis (7 strains), African Sleeping Sickness (9 strains) and Parkinson's disease (1 strain). 
Three strains have exhibited antimicrobial activities and two others on diabetes. The collaboration with RBG, Kew included exploring leaf endophytic fungi from the Iwokrama Forest Reserve, Guyana. Endophytic fungi isolated from living symptomless leaves of 12 tree species yielded 2492 cultures (64 taxa). Isolates were found to have potent anti-insect activity, potent anti-fungal activity and three isolates showed potent anti-bacterial activity. This activity had a hit rate of 1 in 3; with three novel molecules discovered and made ready for development into products (Cannon and Simmons 2001; Kelley et al. 2003). CABI currently lists over 150 projects in crop health (30), development communication and extension (26), digital development (14), invasive species (62), publishing (3), and value chains and trade (20) with over 90 of these utilising microbes (https://www.cabi.org/what-we-do/cabiprojects/).

There are numerous business models that collections implement for sustainability but generally this includes some form of grant or institutional support (Smith et al. 2014). The bulk of the funding for the CABI living collection has come from a mix of culture supply fees, services such as identifications and project revenue. When the UK National Collection of Fungus Cultures was founded in 1947, the collection received a grant of $£ 500$ (Report 1947). The UK partially funded this collection until 1989, by which time dedicated Biochemistry and Industrial Mycology laboratories had been established with the aim of generating revenue lines to sustain the collection (Aitchison and Hawksworth 1993). The collection is supported by CABI expertise: preservation techniques, biosystematics, molecular biology and biochemistry, plant pathology and organism utilisation as biocontrol agents and biopesticides. Over time, as the nature of the expertise has changed and new technologies have evolved, the collection and associated services have had to adapt. The changes in the UK government's support to its various national collections and capabilities have both necessitated rationalization and, in CABI's case, the need to become cost-neutral with a mix of internal support, product and service sales and a portfolio of projects and consultancies. The hidden potential in the 30,000 unique strains that may enable the finding of active molecules and taking them to the market has been of interest to CABI and its partners and still remains to be fully exploited. The whole organisms and their genes can provide microbial solutions to food, health and environmental problems and strengthen the bioeconomy. In its history, CABI provided fungi to the initial studies that led to the discovery of mycoprotein as a human food source. It still holds the original Penicillium deposit by Fleming as well as a penicillin production strain from the early 1940s. Only $25 \%$ of the current holdings are from the UK, with the rest of the strains coming from over 140 countries, the majority from our 49 member countries (https://www.cabi.org/about-cabi/membership/membe $\mathrm{r}$-countries/). CABI is a world leader in preservation of fungi with over 150 publications in the last 10 years on the topic. CABI has helped collections and carried out training in 19 countries including the UK where it runs a training course biennially and directly in China, India, Indonesia, Kenya, Malaysia, Tanzania and Uganda. CABI has run 75 training courses over a 25 -year period across the world with over 1000 participants and with individually designed training programmes for over 50 individual scientists. CABI also shares its knowledge and technology through the supervision of undergraduate and postgraduate students as well as the examination of postgraduate theses for universities including Imperial College, Royal Holloway, University of Aberdeen (all UK) and University of Minho (Portugal).

CABI's work is based on building partnerships of researchers with the expertise and technologies for each specific project and prides itself in converting science into practical solutions for farmers and practitioners. However, it is not just the progress in technology and science that CABI needs to keep pace with. The regulatory environment has a major impact on research and, over the years, CABI has provided support to the UK in the implementation of international agreements concerning genetic resources to which the UK is a party, including:

- The Convention on Biological Diversity

- The Nagoya Protocol on Access to Genetic Resources and the Fair and Equitable Sharing of Benefits Arising from their Utilisation

- The International Treaty on Plant Genetic Resources for Food and Agriculture

- International Plant Protection Treaty

- Trade-related Intellectual Properties agreement under World Trade Organisation

- Cartagena Protocol to the Convention on Biological Diversity

- Convention on International Trade in Endangered Species

- OECD Initiative on biotechnology for sustainable growth and development

This extends out through CABI's activities in its 13 centres, a presence in 21 of its 49 countries and through projects in many other countries. Different country approaches make compliance difficult and practical solutions to the regulatory environment changes require constant monitoring. CABI has addressed the implementation of the Nagoya Protocol by publishing its policy and establishing compliant best practice to meet genetic 
resource provider country requirements (Verkley et al. 2016; Boundy-Mills et al. 2017; McCluskey et al. 2017; Smith 2017; Smith et al. 2017, 2018; Hinz et al. 2019).

\section{Identification and assigning names}

Correct identification of an organism with its accurate scientific name is critical for its use in solving problems. The name provides access to information about that organism and understanding the problem at hand. For example, assignment to hazard group defining containment level for handling organisms and biosecurity restricting access and use require the name to ensure regulation is followed e.g. in the UK (https://www.hse. gov.uk/pubns/misc208.pdf). The approved list of names of bacteria lists all prokaryotic names with standing in nomenclature (LPSN) (http://www.bacterio.net/-alint ro.html), presenting a total of 15,626 species as of 25 May 2017. IndexFungorum (http://www.indexfungorum.org), lists all formal fungal names representing over 120,000 species of Fungi at the time of writing. Culture collections have a role in providing reference strains for comparison enabling unknown isolates to be identified and given a name. Currently, no single site listing all strains in culture and available for comparison or research exists; the closest is the Global Catalogue of Microorganisms (GCM) compiled by the WDCM (http://gcm.wfcc.info/) to which 132 of the 800 plus WDCM registered collections have provided their strain catalogues. The GCM lists 453,336 strains, $14.2 \%$ of the 3.2 million samples available from all 800 collections; 29,573 are species of fungi that are available; this includes synonyms and sexual and asexual names for the same fungus representing $24 \%$ of described species. A substantial gap in available reference strains exists and this gap broadens when also incorporating the species that cannot yet grow outside of their natural environment or host. Estimations for the number of fungi on Earth vary for example, between 3.5 to 5.1 million species, worldwide (Blackwell 2011); it is considered that population genomics will reveal such numbers and potentially more. Recent studies using such technologies suggests otherwise. Wu et al. (2019) suggest 12 million whereas others claim the numbers are vastly overestimated (https://www.sciencedaily.com/relea ses/2015/03/150313083447.htm). Investigations of this hidden resource are underway to get a better understanding of microbe host and environment interaction and enable our harnessing of microbial communities for the advancement of science and improvement in healthcare, food production and the bio-based economy (Ryan et al. 2019). Such work and isolation programmes result in the discovery of many new microorganisms that require maintenance for future use.
Providing the correct name of an organism is essential for samples assigned for deposit in culture collections. Until the advent of molecular methods, identification of fungi to species level was undertaken by CABI's expert team of 'classical' morphometric mycologists, being based primarily on morphological observations using microscopic analysis, comparison with detailed existing species descriptions and use of published taxonomic keys (see further reading). Such methods are heavily reliant upon the fungus being in sporulating condition, with spore morphology, size, shape, colour and ornamentation and method of spore development being important aspects, in addition to such factors as colour, texture and growth rate of colonies on diagnostic media in culture, presence of exudates and soluble pigments and presence or absence of a sexual state. CABI's bacteriology department was established in 1959 to identify plant pathogenic bacteria with identification undertaken by phenotypic characterization using a range of media-based biochemical tests. These identification methods for bacteria were superseded in early 1990s by the introduction of fatty acid analysis using gas liquid chromatography (Aitchison and Hawksworth 1993).

Around the world, molecular sequencing developed by Sanger et al. (1977) gained wide usage for identification of bacteria during the 1980s and for fungi during the early 1990s. This method was introduced at CABI in 2003 and became the established procedure for identification of bacteria, yeasts and filamentous fungi. For bacteria, the standard approach is to sequence part of the 16S rRNA gene subunit. Molecular identification for filamentous fungi is undertaken by sequencing the internal transcribed spacer (ITS) region of the rRNA gene cluster encompassing ITS1-5.8S-ITS2. It is the region which provides the 'DNA barcode' for fungi (Schoch et al. 2012). Results from each sample are matched against global databases of sequenced organisms, and the data interpreted by taxonomic specialists to establish the identity. In cases where determination to species level for fungi cannot be resolved using ITS sequencing additional gene loci are sequenced. An example is in the genus Fusarium (Watanabe et al. 2011) for which, part of the translation elongation factor $1 \alpha$ (TEF) gene is sequenced to provide definitive identification. From DNA-based phylogenetic studies involving multiple locus sequence analysis, it is now recognised that many genera of bacteria and fungi contain groups of closely-related species which were previously thought to be a single species. Such groups of 'cryptic' species are often referred to as 'species complexes.' An example in the case of bacteria is the Bacillus subtilis species complex (Rooney et al. 2009), and in the case of fungi, the Fusarium solani species complex 
(Coleman 2016). Whereas traditional identification methods for fungi and bacteria relied upon the presence of clear visual differences between species, there are an increasing number of new prokaryotic and fungal species which are being assigned on the basis of differences which are only clearly evident at the molecular level.

Since closely-related organisms assigned currently to species complexes were at one time considered to be a single species and were deposited in culture collections under one taxon name, it is now a challenge for culture collections and fungaria to re-assign names. This is the case, particularly, where differences between species are only evident at the molecular level. In the case of fungi, this may involve additional work as either multi-locus or whole genome sequencing is often required for definitive identification of closely-related taxa, since ITS barcode sequencing alone is not always sufficient to distinguish species. Investigations such as these may require a substantial source of funding. A further issue for culture collections is the fact that for many years the asexual and sexual states of fungi were assigned under different genus and species names. This is now not allowed and a single name is now being designated (Hawksworth et al. 2011).

Three main online repositories designated for the formal registration of new fungal names are Index Fungorum (http://www.indexfungorum.org), MycoBank (http://www.mycobank.org) and Fungal Names (http:// www.fungalinfo.net). To underpin taxonomy and the naming of fungi, a core set of data needs to be available, including information on place of publication and deposit of the type specimen. The type must be lodged in a recognised collection as a dried specimen in a fungarium or as a living culture preserved in a metabolically inactive state in a culture collection. MycoBank was launched in 2004 as an online open access repository with the primary aim of registering all fungal taxonomic novelties including new names and combinations and to provide descriptions and illustrations (Crous et al. 2004; Robert et al. 2013). The type strains held within the CABI Culture Collection provide essential reference material. Mycological taxonomy is in a state of flux currently, as individual end-users interpret the 'one fungus $=$ one name' amendment to the Fungal Code in their own ways. It is exacerbated by the present situation where gaps and errors in public sequence databases mean that individuals wishing to place a name on an organism, in order to gain further information on the potential of the organism they have found, may find it difficult to go further. Consulting the fungal BRCs around the world is a good start and revisiting the traditional methods may help. To assist with the latter, a list of further reading is provided in the Reference section.

\section{Cryopreservation of microbiome samples and establishment of an agricultural microbiome resource centre: an example of new and upcoming developments in culture collections}

Microbial preservation research has focused on axenic microorganisms that are readily cultured under standard laboratory conditions (Emerson and Wilson 2009; Prakash et al. 2013; Ryan et al. 2019) with post preservation characterisation using techniques from microbial culture and microscopy to advanced molecular techniques. This has provided a resource of authenticated axenic microorganisms through public service collections and enables scientists to acquire and deposit such microorganisms for their research. A similar resource is not yet available for microbiome samples. Large numbers of deposits of pure microorganisms isolated from microbiome studies are accepted into culture collections (Bai et al. 2015; Browne et al. 2016; Lagkouvardos et al. 2016), there is little published data on the long-term storage of microbial ecology samples of the whole microbiome or consortia despite their increasing application in the biobased economy in the last decade (Kerckhof et al. 2014).

Cryopreservation is seen as the optimal method of the long-term preservation of axenic microorganisms, and is now being applied to microbiome samples at CABI. A current research project is evaluating the effectiveness of cryopreservation as a method to preserve environmental microbiome samples. Success will be tested by subjecting samples to cryopreservation methods and next generation sequencing techniques to characterise the active microbes before and after preservation and at several subsequent time-points to identify changes that occur within microbial communities before and after cryopreservation. The ultimate aim is to identify an optimal method that does not compromise composition or potential functionality and which could be used for longterm storage of microbiome samples.

\section{Examples of key outputs from other fungal BRCs}

A recent consensus statement describes the central role and global importance of microorganisms in climate change biology. It stresses that the impact of climate change will depend heavily on responses of microorganisms, which are essential for achieving an environmentally sustainable future (Cavicchioli et al. 2019).

Microbiologists and their collections of the known microorganisms form the framework for gaining a better understanding of microbial communities and a concerted and consolidated effort is required to enable humanity to harness the full power of microorganisms. Currently it is estimated that we have been able to describe less than $1 \%$ of estimated number of microbial species. We 
now have tools to explore the hidden realm and to organise the study effectively and efficiently through research programmes. The MicrobiomeSupport project (https:// www.microbiomesupport.eu/), the UK Plant Microbiome initiative (https://www.cabi.org/news-article/cabi-androthamsted-research-launch-uk-plant-microbiome-initi ative/) and the International Alliance for Phytobiomes Research (http://www.phytobiomes.org) are amongst recent efforts to draw together researchers and industry end users to gain the best out of the investment being made. It is clear that the global community of public service collections needs to respond to this new opportunity and that microbial domain BRCs have a key role to play in addressing global challenges such as climate change, food security, poverty and healthcare.

Specifically, fungal collections continue to make inroads, their holdings underpin research and they are the source of new science and products. For example, the National Collection of Pathogenic Fungi is a Public Health England culture collection which is supporting the University of Manchester on a project to establish the Aspergillus fumigatus gene-wide knockout collection (COFUN) funded by the Wellcome Trust (http://www. phe-culturecollections.org.uk/COFUN).

COFUN aims to generate knockout mutants for all of the coding genes in the human pathogen Aspergillus fumigatus. In total around 10,000 mutant lines will be generated. The libraries can be used to rapidly identify key genetic factors associated with research interests, validate the outputs from other genome-wide analysis, identify mechanisms of drug resistance and tolerance and enable the undertaking of rapid quantitative parallel fitness analyses.

The Westerdijk Fungal Biodiversity Institute, which is part of the Royal Netherlands Academy of Arts and Sciences (formerly known as the Centraalbureau voor Schimmelcultures; CBS) is situated in Utrecht. This collection maintains over 100,000 strains of microorganisms, representing a large percentage of the species in the fungal kingdom (http://www.wi.knaw.nl/). It is worldrenowned for its Studies in Mycology journal which publishes systematic monographs of filamentous fungi and yeasts. The collection is researched from many aspects and recently Casadevall et al. (2019) reported that the emergence of Candida auris may be related to climate change. This human pathogen emerged simultaneously in three continents with each clade being genetically distinct. The authors suggest it may be the first example of a new fungal disease emerging as a direct result of climate change, with the caveat that many other factors could have contributed.

The American Type Culture Collection (ATCC) describes itself as The Global Bioresource Centre and its strains are collected from key research teams globally. The WDCM entry states they hold 64,000 strains of which 46,000 are fungi including yeasts. They have recently developed Fungal Mock Community Standards for Mycobiome Studies (https://www.lgcstandards-atcc. org/ /media/PDFs/Presentations/2019/ASM\%20Mic robe $\% 202019 \% 20$ Mycobiome $\% 20$ Symposium.ashx). Recognising that a significant amount of work has been performed on the human microbiome and that fungi are ubiquitous and live in symbiosis with the human body, tools are needed to assist in community profiling of fungi. ATCC has developed genomic DNA and whole cell mock microbial communities comprising ten medically relevant fungi to demonstrate the use of standards in evaluating DNA extraction and sequencing methods for mycobiome analysis.

The Agricultural Research Service (ARS) Culture Collection (NRRL) is one of the largest public collections of microorganisms in the world, containing approximately 98,000 isolates of bacteria and fungi. The collection is housed within the Mycotoxin Prevention and Applied Microbiology Research Unit at the National Center for Agricultural Utilization Research in Peoria, Illinois (https ://nrrl.ncaur.usda.gov/). There are a number of recent products utilising the collection strains, these include "Green" surfactants, where sophorolipids from Candida yeasts can provide alternatives for the wetting agents mainly from petroleum. These chemicals have a long list of industrial uses, from detergents and cosmetics to paints and pesticide formulations; about 10 million tons of surfactants are produced annually. Liamocin, a natural fungal oil that kills certain types of bacteria could have potential use in veterinary, medical, industrial, and food applications. Two Streptococcus species responsible for mastitis, an udder infection in cows that costs the U.S. dairy industry $\$ 2$ billion annually, are amongst the pathogens that are susceptible. Additionally, ARS has developed technology to identify mycotoxin-contaminated grain so it can be diverted from the food supply. The technology has been licensed to approximately $30 \mathrm{com}$ panies, helping ensure food safety, free and open trade markets for U.S. grain, and farmer profits.

The WDCM has established the 'Analyzer of Bioresource Citations' (ABC) (http://abc.wfcc.info/) as a platform to discover how strains of member collections have been used. The statistics provided demonstrate that 79,224 strains have been referenced in 145,133 papers; these strains were held by 131 culture collections in 50 countries. Strains from WDCM registered collections have been subject to publications in 50,307 journals from January,1953 until April 2020. These include 42,157 patents in reference to 44,508 strains, 4976 genomes in reference to 4525 strains and 556,264 nucleotide sequences 
in reference to 72,925 strains. CABI living collection has over 2000 strains that are used in industrial applications or that are reference strains in standards.

\section{Discussion and future direction}

The examples of the use of culture collection resources provides a catalogue of useful outputs from single collections. Much more could be achieved if the resources of the 800 WDCM registered collections could be coordinated and the skills of their staff focused on common objectives. The roles of WFCC, MIRRI and the potential of the GBRCN could facilitate this with research funders delegating tasks regarding characterised resource delivery and conservation to underpin their research programmes. Engagement of the collections and their networks of depositors could achieve coordinated and targeted isolation programmes to ensure resources are available to screen for the urgently needed antimicrobials or for biocontrol agents to tackle pests, diseases and invasive species that threaten crop yields and the environment. Bringing microbial resources together requires the implementation of common standards across the partnership to ensure reproducibility and an infrastructure to coordinate activities.

Only when the full capacity of microbial communities is explored using molecular technologies, will the full potential of each microorganism be recognised and harnessed (Lee and Lee 2013; Qui et al. 2019). Similarly, understanding the biology of each fungus and manipulating its growth conditions and extraction processes, before screening for activity, is an essential part of the discovery process for new microbially derived products. This opens up the chemistry that is often missed or overlooked. Using current and future technologies to access the hitherto uncultured organisms will deliver more candidates for the screening process (Brennecke et al. 2018; Smith et al. 2019).

The outputs of microbiology research contribute directly and indirectly to several UN Sustainable Development Goals (SDG) and offer targets for future research:

SDG 1: No Poverty Microbial resources provide indirect opportunities for improved income along value chains through partnerships with industry to develop new products and processes that will deliver jobs and impact on livelihoods.

SDG 3: Good Health and Well-being Microbiology research and the resources generated from it support industry in providing solutions to environmental pollution ensuring healthy lives and promotes well-being for global communities. Using the knowledge gained from examining the human microbiome and designing appropriate microbial interventions is contributing to improving human health. The discovery of antimicrobials is a major area of research today as microorganisms are becoming resistant to the ones we currently use

SDG 8: Decent Work and Economic Growth Linked to SDG 1, the contribution partnerships will have with industry will contribute to sustainable economic growth and full and productive employment.

$S D G$ 9: Industry, Innovation and Infrastructure mBRCs promote inclusive and sustainable industry and foster innovation; playing their part in this by helping provide innovative microbial solutions.

SDG 12: Responsible Consumption and Production Microbiology plays an important role in composting and waste management. Associated studies result in the creation of knowledge systems, technology and knowledge transfer.

SDG 14: Life Below Water Conservation of marine microbes and accessing these difficult to culture organisms can contribute to our understanding and enables sustainable use of the oceans, seas and marine resources for sustainable development and reduce the threat to biodiversity.

SDG 15: Life on Land mBRCs and microbiology research focussed to protect, restore and promote sustainable use of terrestrial ecosystems, sustainably manage forests and combat pollution.

SDG 17: Partnerships for the Goals-Strengthen the means of implementation and revitalize the global partnership for sustainable development The mBRC community can enhance market access and trade, working through public private partnerships and establishing common platforms. The organisms and associated information provided by mBRCs can impact at many levels in achieving the Sustainable Development Goals. No single collection can achieve this alone providing all the more reason why we need to coordinate such effort.

99\% of the microbes are hidden and we are just discovering how we can access them and harness them to the benefit of humankind and the environment. Coordinated effort is needed, both regionally and globally. The MicrobiomeSupport project (https://www.microbiomesuppo rt.eu/) funded by the European Commission, the CABI and Rothamsted initiated Phytobiome initiative (https://www. cabi.org/news-article/cabi-and-rothamsted-research-launc h-uk-plant-microbiome-initiative/) and in the USA the Phytobiomes Alliance (http://www.phytobiomes.org) are investigating how together they might focus research to better understand microbiomes, their modulation and use. The vast amount of knowledge, expertise and resources need to be better harnessed to deliver the solutions society 
needs to secure future sustainability. There are a number of actions that can be taken to provide a better future. As such, a list of recommendations follows:

\section{Recommendations}

\section{Delivering current needs}

- There are gaps in organism coverage and insufficient candidates for high throughput screening for new products for example antimicrobials. A global strategy is needed to ensure organisms that are critical to scientific discoveries are preserved for future use;

- Research funding is scarce with resources and expertise fragmented currently: BRCs need to respond to local challenges and network to get value from investment of public funding;

- The study of microbiomes is accelerating and the benefits of engaging microbial communities recognised. A coordinated effort is required to address storage and access to microbial communities making up the various host and environmental microbiomes and their associated data to support research to facilitate the release of the full potential of microorganisms;

- Key outputs come from research and utilisation of current culture collection holdings continue but gaps remain. Output and value would be enhanced enormously and duplication of effort avoided through coordinated effort;

- Global challenges require global responses, multidisciplinary approaches and a critical mass to resolve. A mechanism to engage the full potential of the microbial resource community (mBRC) in providing resources and solutions to global challenges is required;

- Mycological taxonomy and the naming of organisms has become complex with mixed taxonomies utilised and genome sequence databases incomplete and including erroneous data. mBRCs need to coordinate efforts to play their part in ensuring a comprehensive set of reference strains is available, sharing the coverage rather than duplicating effort, to fill gaps and remove errors.

- Changes in the regulatory environment such as the enactment of the Nagoya Protocol require common compliant approaches

\section{Developing the infrastructure}

- Participating BRCs must operate to international standards to ensure quality and importantly, interoperability of service, function and data;

- Provision of assistance for countries with no or limited infrastructure;
- BRCs need to develop robust business models to secure their sustainability;

- Build upon current initiatives to coordinate mBRC operations such as MIRRI in Europe, USCCN in the USA, the Asian BRC Network to establish a global effort that provides infrastructure to support the efforts of the WFCC;

- Take steps to establish the GBRCN envisaged by the OECD utilising the outputs of the GBRCN demonstration project (Fritze et al. 2012).

\section{Policy, community support and funding}

- Research funders, science publishers, the research community and bioindustry need to work together to develop and implement strategies to make the most of the potential of the hidden microbiology resource and harness the outputs of microbial communities;

- A coordinated approach is required to utilise the limited funding through a research infrastructure and sharing the delivery through its constituent partners as exemplified through the distributed ESFRI research infrastructures in Europe;

- Mechanisms to share resources more openly, such as open access publications, that will allow development and equitable sharing of benefits from discoveries and that accelerates the pace of discovery and innovation to address our common global challenges.

\section{Conclusions}

It is evident that BRCs, specifically microbial culture collections, provide resources that underpin research and many new products and uses of microorganisms have been enabled by the study of organisms from collections. However, this function can be made much more efficient and effective with better coordination and linkage with funders and the research community. Researchers can access the holdings of collections but there is not yet a single platform that holds the information on all strains held. The GCM holds information on only $14 \%$ of the available strains. Collection organisations do their best to coordinate access but more needs to be done to facilitate the uptake and use of organisms and their associated data. The greatest opportunity to be able to understand, harness and moderate the hidden resource of microbial communities (99\% of the microorganisms in the environment) is to coordinate microbiome activities and use the networks of BRCs to achieve this. It is not only the organisms in mBRCs currently that can be provided. There is the potential for coordinating networks of depositors into the collections in targeted isolation programmes to 
provide access to the new organisms, the samples containing them and their potential novel chemistry. A global effort is needed. Most importantly, the establishment of the GBRCN to provide coordinated access and the microbiome research community via appropriate global infrastructures should be undertaken. It has begun in Europe with MIRRI, with further activities by the Asian BRC Network and the USCCN. The foundations for significant advances are in place. Researchers, funders, journal editors and collections need to work together to coordinate strategy and introduce mechanisms to accelerate access to microbial communities essential for our survival and the future of our planet.

\begin{abstract}
Abbreviations
ARS: Agricultural Research Service; ATCC: American Type Culture Collection; BRC: Biological Resource Centre; CABI: CAB International-not normally expanded, formerly Commonwealth Agricultural Bureau now Centre for Agriculture and Bioscience International; CHAP: Centre for Crop Health and Protection; CMI: Commonwealth Mycological Institute; DSMZ: Leibniz Institute DSMZ-German Collection of Microorganisms and Cell Cultures GmbH (Deutsche Sammlung von Mikroorganismen und Zellkulturen); EMbaRC: European Consortium of Microbial Resources Centres; ESFRI: European Strategy Forum for Research Infrastructures; GBRCN: Global biological resource network; GCM: Global catalogue of microorganisms; IMI: International Mycological Institute; ITS: Internal transcribed spacer; LPSN: List of prokaryotic names with standing in nomenclature; mBRC: Microbial domain Biological Resource Centre; MALDI-ToF: Matrix assisted laser desorption/ionization; MS: Mass spectrometry; MIRRI: Microbial resources research infrastructure; NGS: Next generation sequencing; NCWRF: National Collection of Wood-Rotting Macro-Fungi; NMR: Nuclear magnetic resonance; NRRL: Now the ARS culture collection formerly the Northern Regional Research Laboratory of the ARS, US Department of Agriculture; OECD: Organisation for Economic Co-operation and Development; RBG: Royal Botanic Gardens; rRNA: Ribosomal ribonucleic acid; SDG: Sustainable development goal; TEF: Translation elongation factor; UKBRCN: United Kingdom Biological Resource Centre Network; USCCN: United States Culture Collection Network; WDCM: World Data Centre for Microorganisms; WFCC: World Federation for Culture Collections.
\end{abstract}

\section{Acknowledgements}

$C A B I$ is an international intergovernmental organisation, and we gratefully acknowledge the core financial support from our member countries (and lead agencies) including the United Kingdom (Department for International Development), China (Chinese Ministry of Agriculture), Australia (Australian Centre for International Agricultural Research), Canada (Agriculture and Agri-Food Canada), Netherlands (Directorate-General for International Cooperation), and Switzerland (Swiss Agency for Development and Cooperation). See https:// www.cabi.org/about-cabi/who-we-workwith/key-donors/ for full details.

The authors also wish to thank the staff of the World Data Centre for Microorganisms for the data here provided on the WDCM registered collections.

\section{Authors' contributions}

DS gathered the data for the background of the paper and analyzed the WDCM and culture collection data; MJR and AK contributed information on the usage of the $C A B I$ culture collection; $A G B$ provided data on the DTOL, CHAP and aflatoxin projects; GC provided the information on genomics; TSC provided the information on the CABI identification service; All authors contributed to the recommendations and conclusions. All authors read and approved the final manuscript

\section{Funding}

$C A B I$ is an international intergovernmental organisation, and we gratefully acknowledge the core financial support from our member countries (and lead agencies) including the United Kingdom (Department for International
Development), China (Chinese Ministry of Agriculture), Australia (Australian Centre for International Agricultural Research), Canada (Agriculture and AgriFood Canada), Netherlands (Directorate-General for International Cooperation) and Switzerland (Swiss Agency for Development and Cooperation).

\section{Availability of data and materials}

The datasets analyzed during the current study are available in the World Data Centre for Microorganisms repository, http://www.wdcm.org/ and the CABI-IMI Culture Collection, https://www.bioscience.cabi.org/services/cultu re-collection/.

\section{Ethics approval and consent to participate}

Not applicable: The manuscript does not report on or involve the use of any animal or human data or tissue.

\section{Consent for publication}

Not applicable: the manuscript does not contain data from any individual person.

\section{Competing interests}

The authors declare that they have no competing interests.

Received: 6 April 2020 Accepted: 3 June 2020

Published online: 23 June 2020

\section{References}

\section{Primary studies included}

Aitchison EM, Hawksworth DL. IMI: retrospect and prospect. Wallingford: CABI; 1993.

Alba-Lois L, Segal-Kischinevzky C. Yeast fermentation and the making of beer and wine. Nat Educ. 2010;3(9):17.

Bai Y, Müller D, Srinivas G, Garrido-Oter R, Potthoff E, Rott M, Dombrowski N, Münch PC, Spaepen S, Remus-Emsermann M, Hüttel B, McHardy AC, Vorholt JA, Schulze-Lefert P. Functional overlap of the Arabidopsis leaf and root microbiota. Nature. 2015;528:364-9. https://doi.org/10.1038/natur e16192.

Becker $\mathrm{P}$, et al. Public microbial resource centers: key hubs for findable, accessible, interoperable, and reusable (FAIR) microorganisms and genetic materials. Appl Environ Microbiol. 2019;85(21):e01444-19. https://doi. org/10.1128/AEM.01444-19.

Blackwell M. The fungi: 1, 2, 3 . . 5.1 million species? Am J Bot. 2011;98:426 Baeshen NA, Baeshen MN, Sheikh A, Bora RS, Ahmed MMM, Ramadan HAl, Saini KS, Redwan EM. Cell factories for insulin production. Microb Cell Fact. 2014;13:41. https://doi.org/10.1186/s12934-014-0141-0.

Boundy-Mills K, Smith D, McCluskey K, Greene S, Duke C. International treaty affects microbiology research. Microcosm. 2017;1(Fall 2017):82-5.

Boundy-Mills K, McCluskey K, Elia P, Glaeser JA, Lindner DL, Nobles DR Jr, Normanly J, Ochoa-Corona FM, Scott JA, Ward TJ, Webb KM, Webster K, Wertz JE. Preserving US microbe collections sparks future discoveries. J Appl Microbiol. 2019. https://doi.org/10.1111/jam.14525.

Brennecke P, Ferrante MI, Johnston IA, Smith D. A collaborative European approach to accelerating translational marine science. J Mar Sci Eng. 2018. https://doi.org/10.3390/jmse6030081.

Browne HP, Forster SC, Blessing OA, Kumar N, Neville BA, Stares MD, Goulding D, Lawley TD. Culturing of 'unculturable' human microbiota reveals novel taxa and extensive sporulation. Nature. 2016;533:543-6.

Buddie AG, Bridge PD, Kelley J, Ryan MJ. Candida keroseneae sp. nov., a novel contaminant of aviation kerosene. Lett Appl Microbiol. 2010;52:70-5.

Buddie AG, Crozier J, Rutherford MA, Flood J, Bridge D. Population development within the coffee wilt pathogen Gibberella xylarioides reflects hostrelated divergence. Eur J Plant Pathol. 2015;42:291-304.

Cafá G, Caggiano B, Reeve MA, Bhatti H, Honey SF, Bajwa B, Buddie AG. A polyphasic approach aids early detection of potentially toxigenic aspergilli in soil. Microorganisms. 2018. https://doi.org/10.3390/microorganisms7 090300.

Cameron KH, Somachandra KP, Curry CN, Jenner WH, Hobbs SLA. Delivering actionable plant health knowledge to smallholder farmers through the plantwise program. J Agric Food Inf. 2016;17(4):212-29. https://doi. org/10.1080/10496505.2016.1211530. 
Cannon PF, Simmons CM. Diversity and host preference of leaf endophytic fungi in the Iwokrama Forest Reserve, Guyana. Mycologia. 2002;94:210-20.

Casadevall A, Kontoyiannis DP, Robert V. On the emergence of Candida auris: climate change, azoles, swamps, and birds. mBio. 2019. https://doi. org/10.1128/mbio.01397-19.

Cavicchioli R, Ripple WJ, Timmis KN, et al. Scientists' warning to humanity: microorganisms and climate change. Nat Rev Microbiol. 2019. https://doi. org/10.1038/s41579-019-0222-5.

Coleman JJ. The Fusarium solani species complex: ubiquitous pathogens of agricultural importance. Mol Plant Pathol. 2016. https://doi.org/10.1111/ mpp.12289.

Crous PW, Gams W, Stalpers JA, Robert V, Stegehuis G. MycoBank: an online initiative to launch mycology into the 21 st century. Stud Mycol. 2004;50:19-22.

Das S. (ed) Microbial biodegradation and bioremediation. 1st ed. Amsterdam: Elsevier; 2014. ISBN: 9780128000212.

Demain A, Sanchez S. Microbial drug discovery: 80 years of progress. J Antibiot. 2009. https://doi.org/10.1038/ja.2008.16.

Emerson D, Wilson W. Giving microbial diversity a home. Nat Rev Microbiol. 2009;7:758.

Fenster K, Freeburg B, Hollard C, Wong C, Laursen RR, Ouwehand AC. The production and delivery of probiotics: a review of a practical approach. Microorganisms. 2019. https://doi.org/10.3390/microorganisms7030083.

Fritze D, Martin D, Smith D. Final report on the GBRCN Demonstration Project. Germany: GBRCN Secretariat; 2012. ISBN 978-3-00-038121-8.

Hawksworth DL, Crous PW, Redhead SA, et al. The Amsterdam declaration on fungal nomenclature. IMA Fungus. 2011. https://doi.org/10.5598/imafu ngus.2011.02.01.14.

Hawksworth DL, Lücking R. Fungal diversity revisited: 2.2 to 3.8 million species. Microbiol Spectr. 2017. https://doi.org/10.1128/microbiolspec. funk-0052-2016.

Hinz H, Weyl P, Smith D, Djeddour D. The Nagoya Protocol: implications for classical biological control of invasive plant species. In: Hinz H, Bon M-C, Bourdôt G, Cristofaro M, Desurmont G, Kurose D, Müller-Schärer H, Rafter M, Schaffner U, Seier M, Sforza R, Smith L, Stutz S, Thomas S, Weyl $P$, Winston $R$, editors. XV international symposium on biological control of weeds. Engelberg, Switzerland 26-31 August 2018, pp 206-211. 2019; https://bugwoodcloud.org/resource/files/15115.pdf.

Jay JM, Loessner MJ, Golden DA. Review of modern food microbiology. 7th ed. New York: Springer Science \& Business Media; 2005. ISBN 0-387-23180-3.

Jozala AF, Costa Geraldes D, Tundisi LL, de Araújo Feitosa V, Breyer CA, Cardoso SL, Mazzola PG, de Oliveira-Nascimento L, de Oliveira Rangel-Yagui C, de Oliveira Magalhães P, de Oliveira MA, Pessoa A. Biopharmaceuticals from microorganisms: from production to purification. Braz J Microbiol. 2016;47(Suppl 1):51-63. https://doi.org/10.1016/j.bjm.2016.10.007.

Kelley J, Cannon P, Simmonds M, Pingal R, Simmons C. The Iwokrama programme: an approach to the sustainable exploitation of genetic resources. In: Lima N, Smith D, editors. Biological resource centres and the use of microbes. XXII ECCO meeting proceedings book; 2003. p. 185-95

Kerckhof FM, Courtens E, Geirnaert A, Hoefman S, Ho A, Vargas VR, Piepe DH Jauregui R, Vlaeminck S, Wiele VD, Vandamme P, Heylen K, Boon N. Optimized cryopreservation of mixed microbial communities for conserved functionality and diversity. PLoS ONE. 2014;9(6):e99517.

Kreyenschulte D, Krull R, Margaritis A. Recent advances in microbial biopolymer production and purification. Crit Rev Biotechnol. 2014. https://doi. org/10.3109/07388551.2012.743501.

Lagkouvardos I, Pukall R, Abt B, Foesel BU, Meier JP, Kumar N, Bresciani A, Martínez I, Just S, Ziegler C, Brugiroux S, Garzetti D, Wenning M, Thi PNB, Wang J, Hugenholtz F, Plugge CM, Peterson DA, Hornef MW, Baines JF, Smidt H, Walter J, Kristiansen K, Nielsen HB, Haller D, Overmann J, Stecher $\mathrm{B}$, Clavel T. The mouse intestinal bacterial collection (miBC) provides hostspecific insight into cultured diversity and functional potential of the gut microbiota. Nat Microbiol. 2016;1:16131.

Lee $\mathrm{MH}$, Lee S-W. Bioprospecting potential of the soil metagenome: novel enzymes and bioactivities. Genomics Inform. 2013. https://doi. org/10.5808/GI.2013.11.3.114.

Louca S, Mazel F, Doebeli M, Parfrey LW. A census-based estimate of earth's bacterial and archaeal diversity. PLoS Biol. 2019;17(2):e3000106. https:// doi.org/10.1371/journal.pbio.3000106.
Martin D, Stackebrandt E, Smith D. MIRRI promoting quality management systems for microbiology. EC Microbiol. 2015;2(2):278-87.

McCluskey K, Barker KB, Barton HA, Boundy-Mills K, Brown DR, Coddington JA, Cook K, Desmeth P, Geiser D, Glaeser JA, Greene S, Kang S, Lomas MW, Melcher U, Miller SE, Nobles DR Jr, Owens KJ, Reichman JH, da Silva M, Wertz J, Whitworth C, Smith D. The US culture collection network responding to the requirements of the Nagoya protocol on access and benefit sharing. mBio. 2017;8:e00982-17. https://doi.org/10.1128/ mbio.00982-17.

Overmann J, Smith D. Microbial resource centers contribute to bioprospecting of bacteria and filamentous microfungi. In: Topics in biodiversity and conservation, vol. 16, 2017 Editor-in-Chief, Professor David Hawksworth. Bioprospecting - successes, potential and constraints Eds Russell Paterson \& Nelson. Berlin: Springer; 2017. p 51-79. ISBN: 978-3-319-47933-0 (Print) 978-3-319-47935-4. https://doi.org/10.1007/978-3-319-47935-4.

Prakash O, Nimonkar Y, Shouche YS. Practice and prospects of microbial preservation. FEMS Microbiol Lett. 2013;339(1):1-9.

Qiu Z, Egidi E, Liu H, Kaur S, Singh BK. New frontiers in agriculture productivity: optimised microbial inoculants and in situ microbiome engineering. Biotechnol Adv. 2019. https://doi.org/10.1016/j.biotechadv.2019.03.010.

Report. Specialist conference on culture collections of micro-organisms. (S.O. Code No. 47-139.) London: HMSO; 1947.

Robert V, Vu D, Amor ABH, van de Wiele N, Brouwer C, Jabas B, et al. MycoBank gearing up for new horizons. IMA Fungus. 2013;4(2):371-9.

Rooney AP, Price NPJ, Ehrhardt C, Swezey JL, Bannan JD. Phylogeny and molecular taxonomy of the Bacillus subtilis species complex and description of Bacillus subtilis subsp. inaquosorum subsp. nov. Int J Syst Evol Microbiol. 2009;59(10):2429-36. https://doi.org/10.1099/ijs.0.009126-0.

Ryan MJ, Ritchie BJ, Smith D. Maintenance and storage of fungal plant pathogens. In: Lane C, Beales P, Hughes K, editors. Fungal plant pathogensprinciples and protocols. Wallingford: CAB International; 2012. ISBN: 978 1845936686 (pbk). http://bookshop.cabi.org/?page=2633\&pid=2265 $\&$ site $=191$.

Ryan MJ, Kasulyte-Creasey D, Kermode A, Phue San S, Buddie AG. Controlled rate cooling of fungi using a stirling cycle freezer. Cryo-Lett. 2014;35(1):63-9.

Ryan MJ, McCluskey K, Verkleij G, Smith D. Fungal biological resources to support international development: challenges and opportunities. World J Microb Biotechnol. 2019;35:139. https://doi.org/10.1007/s1127 4-019-2709-7.

Sanger F, Nicklen S, Coulson AR. DNA sequencing with chain-terminating inhibitors. Proc Natl Acad Sci USA. 1977;74:5463-7. https://doi. org/10.1073/pnas.74.12.5463.

Sly LI, lijima T, Kirsop BE. 100 years of culture collections. In: Proceedings of the Kral symposium to celebrate the centenary of the first recorded service collection, September 13, 1990, International House, Osaka, WFCC, Institute of Fermentation, Osaka, Japan.

Schoch CL, Seifert KA, Huhndorf S, Robert V, Spouge JL, Levesque CA, Chen W. Nuclear ribosomal internal transcribed spacer (ITS) region as a universal DNA barcode marker for Fungi. Proc Natl Acad Sci USA. 2012;109(16):6241-6. https://doi.org/10.1073/pnas.1117018109.

Smith D. Culture collections. Adv Appl Microbiol. 2012;79:73-118.

Smith D. 4.2 practical and implementable mechanisms for compliance with the Nagoya protocol: access and benefit sharing. In: Mason, PG, Gillespie $D R$, Vincent C, editors. Proc. 5th international symposium on biological control of arthropods. Wallingford: CAB International; 2017. ISBN: 9781 78639411 8; Only available as an Open Access eBook http://www.cabi. org/cabebooks/ebook/20173267430.

Smith D, da Silva M, Jackson J, Lyal C. Explanation of the Nagoya protocol on access and benefit sharing and its implication for microbiology. Microbiology. 2017;163:289-96. https://doi.org/10.1099/mic.0.000425.

Smith D, Fritze D. European Culture Collections - the future is MIRRI. Microbiol Today. 2010;37(4):256-8.

Smith D, Hinz H, Mulema J, Wey P, Ryan MJ. Biological control and the Nagoya Protocol on access and benefit sharing - a case of effective due diligence. Biocontrol Sci Technol. 2018. https://doi.org/10.1080/09583 157.2018.1460317.

Smith D, Fritze F, Stackebrandt E. Public service collections and biological resource centres of microorganisms. In: Rosenberg E, De Long EF, Lory $\mathrm{S}$, Stackebrandt E, Thompson F, editors. The prokaryotes-prokaryotic 
biology and symbiotic associations. Berlin: Springer; 2013. p. 267-304 https://doi.org/10.1007/978-3-642-30194-0_14.

Smith D, McCluskey K, Stackebrandt E. Culture collection funding models and BRC business plans, vol. 3. Berlin: SpringerPlus; 2014. p. 81. http://www. springerplus.com/content/3/1/81.

Smith D, Onions AHS. The preservation and maintenance of living fungi, second edition IMI Technical Handbooks 2. Wallingford: CAB International; 1994.

Smith D, Buddie AG, Goss R, Overmann J, Lepleux C, Brönstrup M, Kloareg B, Meiners T, Brennecke P, lanora A, Bouget F-Y, Gribbon P, Pina M. Marine resources for discovery pipelines - an ocean of opportunity for biotechnology? World J Microbiol Biotehnol. 2019. https://doi.org/10.1007/s1127 4-019-2685-y.

Stackebrandt E. Diversification and focusing: strategies of microbial culture collections. Trends Microbiol. 2010;18:283-7.

Stackebrandt E, Smith D, Casaregola S, Varese GC, Verkleij G, Lima N, Bridge PD. Deposit of microbial strains in public service collections as part of the publication process to underpin good practice in science, vol. 3. SpringerPlus 2014. p. 208. http://www.springerplus.com/content/3/1/208.

Verkley G, Martin D, Smith D. Microbial resource research infrastructure best practice manual on access and benefit sharing, published on line MIRRI. 2016. https://zenodo.org/record/284881, https://doi.org/10.5281/zenod 0.284881 and ABSCH November 2016: https://absch.cbd.int/api/v2013/ documents/F1C80F1C-1EB7-F02A-CEED-E7D523F17079/attachments/ MIRRI\%20ABS\%20Manual_web.pdf http://www.mirri.org/fileadmin/mirri/ media/Dokumente/generalDocs/MIRRI_ABS_Manual_web.pdf.

Watanabe M, Yonezawa T, Lee K, Kumagai S, Sugita-Konishi Y, Goto K, Hara-Kudo Y. Molecular phylogeny of the higher and lower taxonomy of the Fusarium genus and differences in the evolutionary histories of multiple genes. BMC Evol Biol. 2011;11(1):322. https://doi. org/10.1186/1471-2148-11-322.

Wu B, Hussain M, Zhang W, Stadler M, Liu X, Xiang M. Current insights into fungal species diversity and perspective on naming the environmental DNA sequences of fungi. Mycology. 2019. https://doi.org/10.1080/21501 203.2019.1614106.

\section{Web links and URLs}

CAB International (CABI). https://www.cabi.org/. Accessed 4 Apr 2020.

Wellcome Trust's Darwin Tree of Life project. https://www.sanger.ac.uk/scien ce/programmes/tree-of-life. Accessed 4 Apr 2020.

Conidia FUELSTAT. https://conidia.com/. Accessed 4 Apr 2020

Fermented Foods; Science Direct. https://www.sciencedirect.com/topics/ food-science/fermented-food. Accessed 4 Apr 2020.

World Federation for Culture Collections (WFCC). http://www.wfcc.info/index php/home/. Accessed 4 Apr 2020.

The World Federation for Culture Collections Guidelines for the Establishment and Operation of Culture Collections. http://www.wfcc.info/guidelines/. Accessed 4 Apr 2020

Common access to biological resources and information, guidance. http:// www.cabri.org/. Accessed 4 Apr 2020.

OECD biological resource task force best practice guidelines for BRCs. http:// www.oecd.org/sti/emerging-tech/oecdbestpracticeguidelinesforbiolog icalresourcecentres.htm. Accessed 4 Apr 2020.

OECD best practice guidelines for BRCs. http://www.oecd.org/sti/emergingtech/38777417.pdf. Accessed 4 Apr 2020.

Towards a global biological resource centre network. http://www.oecd.org/ science/emerging-tech/towardsaglobalbiologicalresourcecentrenetwork .htm. Accessed 4 Apr 2020.

European strategy forum on research infrastructures. https://www.esfri.eu/esfri -roadmap. Accessed 4 Apr 2020.

Plantwise knowledge bank. https://www.plantwise.org/KnowledgeBank. Accessed 4 Apr 2020.

CABI: What we do: projects. https://www.cabi.org/what-we-do/cabi-projects/. Accessed 4 Apr 2020.

CABI: Member Countries. https://www.cabi.org/about-cabi/membership/ member-countries/. Accessed 4 Apr 2020.

HSE: The approved list of biological agents: advisory committee on dangerous pathogens. https://www.hse.gov.uk/pubns/misc208.pdf. Accessed 4 Apr 2020
List of prokaryotic names with standing in nomenclature (LPSN). http://www. bacterio.net/-alintro.html. Accessed 4 Apr 2020.

Science daily: number of fungal species has been greatly overestimated. https://www.sciencedaily.com/releases/2015/03/150313083447.htm. Accessed 4 Apr 2020.

Index Fungorum. http://www.indexfungorum.org. Accessed 4 Apr 2020. MycoBank. http://www.mycobank.org. Accessed 4 Apr 2020.

Fungal Names Registration, China. http://www.fungalinfo.net. Accessed 4 Apr 2020.

The MicrobiomeSupport project. https://www.microbiomesupport.eu/. Accessed 4 Apr 2020.

UK Plant Microbiome initiative. https://www.cabi.org/news-article/cabi-androthamsted-research-launch-uk-plant-microbiome-initiative/. Accessed 4 Apr 2020

International Alliance for Phytobiomes Research. www.phytobiomes.org Accessed 4 Apr 2020

Aspergillus fumigatus gene-wide knockout collection (COFUN): Wellcome Trust. http://www.phe-culturecollections.org.uk/COFUN. Accessed 4 Apr 2020.

Westerdijk Fungal Biodiversity Institute: formerly Centraalbureau voor Schimmelcultures (CBS). http://www.wi.knaw.nl/. Accessed 4 Apr 2020.

The American Type Culture Collection (ATCC): Fungal Mock Community Standards for Mycobiome Studies. https://www.lgcstandards-atcc.org/ /media /PDFs/Presentations/2019/ASM\%20Microbe\%202019\%20Mycobiom e\%20Symposium.ashx. Accessed 4 Apr 2020.

World Data Centre for Microorganisms (WDCM): Analyzer of Bio-resource Citations (ABC). http://abc.wfcc.info/. Accessed 4 Apr 2020.

UKBRCN - United Kingdom Biological Resource Centre Network. https://www. ukbrcn.org/. Accessed 19 May 2020.

Global Catalogue of Microorganisms (GCM). http://gcm.wfcc.info/.

\section{Further reading in mycology}

Alexopoulos CJ, Mims CW, Blackwell M. Introductory mycology. 4th ed. London: Wiley; 1995.

Ainsworth GC, Sparrow FK, Sussman AS. The fung An advanced treatise, vol. 4A, 4B. London: Academic Press; 1973.

von Arx JA. Genera of fungi sporulating in pure culture. 3rd ed. Vaduz: J Cramer; 1980.

von Arx JA, Müller E. Die Gattungen von amerosporen Pyrenomyceten. Beiträge zur Kryptogamenflora der Schweiz. 1954;111:1-434.

Barnet HL, Hunter BB. Illustrated genera of imperfect fungi. 4th ed. London: Collier Macmillan Publishers; 1998.

Barr ME. Prodromus to the class Loculoascomycetes. Amherst: The Author: 1987. p. 168.

Barron GL. Genera of hyphomycetes from soil. Florida: Robert E Krieger Publishing Company; 1968.

Breitenbach J, Kränzlin F. Fungi of Swtzerland. vol. 1 Ascomycetes. Edition Mykologia, Lucerne (Also available in French and German)—1981 and subsequent volumes.

Campbell CK, Johnson EM, Philpot CM, Warnock DW. Identification of pathogenic fungi. London: Public Health Laboratory Service; 1996.

Carmichael JW, Kendrick WB, Conners IL, Sigler L. Genera of hyphomycetes. Edmonton: The University of Alberta Press; 1980.

de Hoog GS, Guarro J. Atlas of clinical mycology. Baar and Delft: Centraalbureau vor Schimmelcultures; 1995. ISBN: 909-70351-26-9.

Domsch KH, Gams W, Anderson TH. Compendium of soil fungi, vol. 1, 2. 2nd ed. London: Academic Press; 1993.

Ellis MB. Dematiaceous hyphomycetes. Kew: International Mycological Institute; 1971.

Ellis MB. More dematiaceous hyphomycetes. Kew: International Mycological Institute; 1976

Ellis MB, Ellis JP. Microfungi on land plants an identification handbook. Richmond: The Richmond Publishing Co Ltd.; 1997.

Ellis MB, Ellis JP. Microfungi on miscellaneous substrates an identification handbook. Richmond: The Richmond Publishing Co Ltd.; 1998.

Eriksson OE. The families of bitunicate ascomycetes. Opera Botanica. 1981:60:1-220

Gams W, Hoekstra ES, Aptroot A. CBS course of mycology. 4th ed. Utrecht: Centraalbureau voor Schimmelcultures; 1998. 
Gravesen S, Frisvad JC, Samson RA. Microfungi. Einer Munksgaard. 1994. ISBN 87-16-11436-1; order from Richmond Publishers.

Hanlin RT. Illustrated genera of Ascomycetes. St. Paul: APS Press; 1990.

Hawksworth DL, Kirk PM, Sutton BC, Pegler DN. Ainsworth and Bisby's dictionary of the fungi. 8th ed. Egham: International Mycological Institute; 1995.

Kohlmeyer J, Kohlmeyer E. Marine mycology — the higher fungi. New York: Academic Press: 1979.

Müller E, von Arx JA. Die Gattungen von didymosporen Pyrenomyceten. Beiträge zur Kryptogamenflora der Schweiz. 1962;1 1(2):1-902.

O'Donnel KL. Zygomycetes in culture. Athens: University of Georgia; 1979.

Raper KB, Thom C. A manual of the Penicillia. Baltimore: Williams \& Wilkins; 1949. p. 1-878.

Samson RA, van Reenen-Hoekstra ES. Introduction to food-borne fungi. 5th ed. Utrecht: Centraalbureau voor Schimmelcultures; 1996.

Samson RA, Evans HC, Latge JD. Atlas of entomopathogenic fungi. Berlin: Springer; 1988.

Singer R. The Agaricales in modern taxonomy. 4th ed. Koenigstein: Koeltz Scientific Books; 1986

Sivanesan A. The bitunicate Ascomycetes and their anamorphs. Vaduz: J Cramer; 1984
Sutton BC. The Coelomycetes. Kew: Commonwealth Mycological Institute; 1990.

Thom C, Church MB. The Aspergilli. Philadelphia: The Williams \& Wilkins company; 1962.

Thom C. The Penicillia. Baltimore: Williams \& Wilkins; 1930.

Webster J. Introduction to fungi. 2nd ed. Cambridge: Cambridge University Press; 1980

\section{Publisher's Note}

Springer Nature remains neutral with regard to jurisdictional claims in published maps and institutional affiliations.
Ready to submit your research? Choose BMC and benefit from:

- fast, convenient online submission

- thorough peer review by experienced researchers in your field

- rapid publication on acceptance

- support for research data, including large and complex data types

- gold Open Access which fosters wider collaboration and increased citations

- maximum visibility for your research: over 100M website views per year

At BMC, research is always in progress.

Learn more biomedcentral.com/submissions 